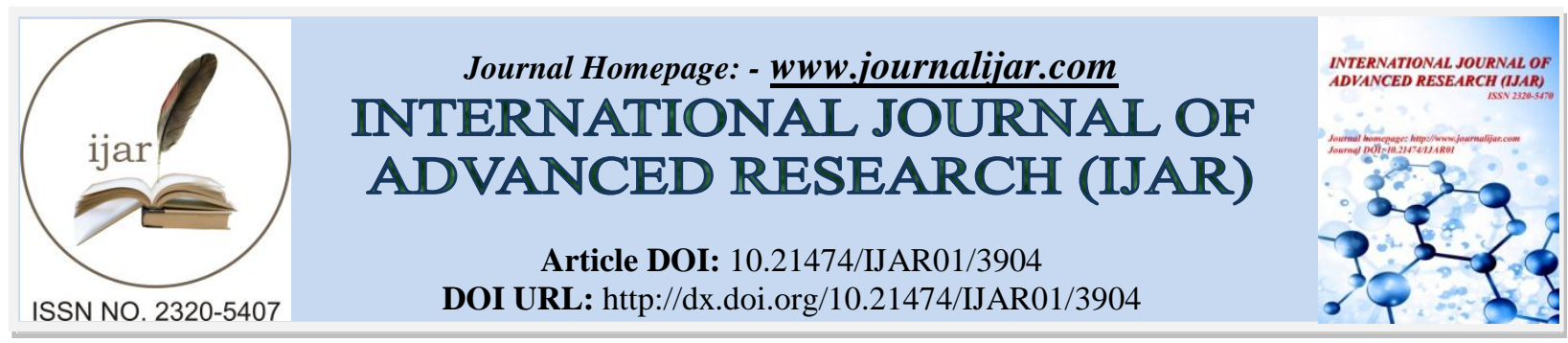

RESEARCH ARTICLE

\title{
DEFLUORIDATION OF WATER USING MUSA ORNATA HUSK NANO HYDROXYAPATITE- ALGINATE BIOCOMPOSITE.
}

*R. Vashantha, Jeyavathana Samuel and D. Thamizharasi.

Department of Chemistry, Anna Adarsh College for Women, Chennai 600040, India.

\section{Manuscript Info}

Manuscript History

Received: 07 February 2017

Final Accepted: 08 March 2017

Published: April 2017

Key words:-

Fluoride; Nano-hydroxyapatite Alginate;

Biocomposite; Adsorption;

Thermodynamic parameters.

\begin{abstract}
In this research work, a new biocomposite namely MOH@n-HAp/Alg biocomposite was developed by the musa ornata husk on nanohydroxyapatite (n-HAp)/ alginate (Alg) biocomposite for defluoridation in batch mode. The synthesized biocomposite possess an enhanced defluoridation capacity (DC). The structural changes of the adsorbent, before and after fluoride sorption were studied using FTIR, XRD and SEM with EDAX techniques. There are various physico-chemical parameters such as contact time, $\mathrm{pH}$, co-existing anions, initial fluoride concentration and temperature were optimized for maximum fluoride removal. The equilibrium data was well modeled by Freundlich, Temkin, D-R and Langmuir isotherms. The present systems follows Freundlich isotherm model. The thermodynamic parameters revealed the nature of adsorption are feasible, spontaneous and endothermic nature of fluoride sorption. The efficiency of the adsorbent material was examined with polluted water samples using the standard procedure.
\end{abstract}

Copy Right, IJAR, 2017,. All rights reserved.

\section{Introduction:-}

Fluoride has been considered as an essential mineral in our body. A very trace amount of fluoride is beneficial for the maintenance of healthy bones and teeth in human body (M.R. Boldaji et al, 2009). The permissible limit of fluoride level in drinking water is in between 0.5 and $1.5 \mathrm{mg} / \mathrm{L}$, which is established by the WHO, may give rise to the prevalence of dental fluorosis and skeletal damage in both children and adults(Y.C.Lu et al, 2002) and its accumulation for a long period of time can alter the DNA structure (M. Maharamanlighu et al, 2002, T.J. Song, 1978). Several methods like adsorption (V.Sivasankar et al, 2010, A.Sivakamy et al, 2001) precipitation (A.K.Chaturredi et al, 1990) ion exchange(N. Azhar et al, 2000) electro-dialysis (M.Castel et al, 2000, Z.Amor et $\mathrm{al}, 2001)$ and electrochemical methods(Al E. Shen et al, 2003) were developed to remove the fluoride from water. The choice of a treatment technique usually depends on the concentration of the fluoride ions, chemical species in the water source, operation costs, waste management and technical versatility. Limitations in terms of cost, production of significant amounts of waste and difficulties in end-use applications of some of the current treatment techniques have prompted the search for environmentally benign reliable and low cost alternation. Adsorption is an economical efficient and applicable technology for fluoride removal from drinking water (S.O. Lesmana et al, 2009). Biosorption is the one of the environmental friendly techniques which minimize the operation cost and make the adsorption technology more eco-friendly and feasible. In this scenario, scientists have paid increased attention on the development of bioadsorbents using the chitosan, chitin, tamarind fruit shell, neem leaf, aliginate, cellulose etc for the removal of toxic ions from the aqueous solution (Varma, A.J et al, (2004), Viswanathan et al, 2009 a, 
Jayakumar et al, 2009, Sairam Sundaram et al, 2009, Googerdchian et al, 2012, Yu, X et al, 2013, Pandi, K et al, 2014, V.Sivasankar et al, 2010, Rajan $\mathrm{Kr}$ et al, 2015). The nano biocomposites have unique properties for the valuable applications in removal of fluoride from the environment. Very small size of nano-particles creates a large surface are in relation to their volume, which makes them highly reactive, compared to non-nano forms of the same sorbents. The ultimate aim of the present work is to develop low cost, eco-friendly and functionalized wasted biomaterials for fluoride removal. Based on the above aspiration, the authors have synthesized nanohydroxyapatite-Alginate biocomposite for defluoridation of water in batch mode studies. The sorption studies were carried out to optimize various equilibrating conditions like $\mathrm{pH}$, contact time, different initial fluoride concentration, interfering anions and temperature. The equilibrium data was filled with various isotherms and kinetic models. The thermodynamic parameters viz., $\Delta \mathrm{G}^{\circ}, \Delta \mathrm{H}^{\circ}$ and $\Delta \mathrm{S}^{\circ}$ have also been calculated and interpreted. The suitability of the developed MOH@n-HAp/Alg biocomposite was tested with a water sample collected from a nearby fluoride endemic village.

\section{Materials and Methods:-}

Materials Sodium alginate, ammonium di hydrogen ortho phosphate, calcium chloride di hydrate, ammonia solution and sodium fluoride and all other were used AR grade.

\section{Synthesis of musa ornata husk nano hydroxyapatite-Alginate biocomposite (MOH@n-HAp/Alg):-}

Banana flower botanically known as musa ornata belongs to the family of musaceae and plantae kingdom. Banana flower husks were collected and thoroughly washed with double distilled water, further dried in the air. The dried husks were powdered sieved into the fractions measuring from BSS52. The MOH@n-HAp/Alg biocomposite was prepared by $2 \%(\mathrm{w} / \mathrm{v})$ concentration of sodium alginate was dissolved in double distilled water and the dried powder was mixed with in the ratio of $1: 1$ at $40^{\circ} \mathrm{C}$ and continuously stirred for 2 hours. Then $20 \mathrm{ml}^{\circ} 1 \mathrm{M} \mathrm{NH}_{4} \mathrm{H}_{2} \mathrm{PO}_{4}$ solution was added and stirred for one hour at $40^{\circ} \mathrm{C}$. The $\mathrm{pH}$ of the medium was adjusted to using $25 \%$ of ammonia solution. Therefore, $20 \mathrm{ml}$ of $1 \mathrm{M} \mathrm{CaCl}_{2} \cdot 2 \mathrm{H}_{2} \mathrm{O}$ solution was added to the above mixture at the same temperature and stirred for one hour. The formed biocomposite was kept aside for 24 hours and the filtered washed with plenty amount of distilled water and dried at $80^{\circ} \mathrm{C}$ for $24 \mathrm{hrs}$ in an oven. The dried biocomposite crushed into fine powder and then used for fluoride sorption studies.

\section{Fluoride adsorption experiments:-}

The synthesized material (MOH@n-HAp/Alg) biocomposite were used as adsorbents for the removal of fluoride from the aqueous solution by the batch equilibrium method in duplicate. Experiments were conducted by adding $0.1 \mathrm{~g}$ of biocomposite sorbent into $100 \mathrm{~mL}$ of $5 \mathrm{mg} / \mathrm{L}$ sodium fluoride solution with a constant speed of $200 \mathrm{rpm}$ at room temperature. At a range of time intervals, the sorbent was separated and the concentration of fluoride was determined. The solution of $0.1 \mathrm{M} \mathrm{HCl}$ and $0.1 \mathrm{M} \mathrm{NaOH}$ was used for $\mathrm{pH}$ adjustment. In isotherm studies, $100 \mathrm{~mL}$ of different initial fluoride concentration $(3,5,7,9,11$ and $13 \mathrm{mg} / \mathrm{L})$ was stirred with $0.1 \mathrm{~g}$ of biocomposite adsorbent dosage in a thermostat shaker in the temperature range of 301,311 and $321 \mathrm{~K}$ at neutral $\mathrm{pH}$. The sorbent was separated and the fluoride concentration was analyzed. The defluoridation capacity(DC) can be calculated by

Defluoridation capacity $=\mathrm{C}_{\mathrm{i}}-\mathrm{C}_{\mathrm{e}} \mathrm{XV} / \mathrm{m}$

Percentage of removal $=\mathrm{C}_{\mathrm{i}}-\mathrm{C}_{\mathrm{e}} / \mathrm{C}_{\mathrm{i}} \mathrm{X} 100$

Where $C_{i}$ and $C_{e}$ were initial and final fluoride concentration in $\mathrm{mg} / \mathrm{L}$, ' $\mathrm{m}$ ' is the mass of the sorbent $(\mathrm{g})$ and $\mathrm{V}$ is the volume of solution(L).

\section{Analytical Methods:-}

The fluoride determination was done by photometric method at 570nm using the UV-Visible spectrophotometer. The $\mathrm{pH}$ measurements were done with the $\mathrm{pH}$ meter of the Susma $\mathrm{pH}$ meter. All other water quality parameters were investigated using standard methods (APHA, 2005).

\section{Characterization Studies:-}

Fourier Transform Infrared (FTIR) spectra of the composite were carried out on Shimadzu IR Affinity 1 model to confirm the functional groups present in it. Surface morphology of the composite was examined with scanning electron microscope(SEM) with Vega3 Tescan model fitted with an energy dispersive X-ray analyzer (EDAX) which allows a qualitative detection and the localization of elements present in the composites (EDAX-Bruker nano GMBH, Germany). SEM images enable a direct observation of the surface of the before and after fluoride-sorbed composite. X-ray diffraction (XRD) measurements were obtained using XRD 3003TT, GE, Inspection Technology 
model to determine the crystalline phases present in the sorbents. The $\mathrm{pH}$ at zero point of charge $\left(\mathrm{pH}_{\mathrm{zpc}}\right)$ of the sorbents was determined by the $\mathrm{pH}$ drift method (Lopez-Ramon et al, 1999).

Computations were made using Microcal Origin software. The best fit is discussed using error bar plot, regression correlation co-efficient $\left(\mathrm{r}^{2}\right)$ and standard deviation.

\section{Results and discussion:-}

Characterization of the composite:-

FTIR analysis:-

Figure 1:- FTIR spectra of (a) MOH@n-HAp/Alg and (b) fluoride sorbed MOH@n-HAp/Alg biocomposite
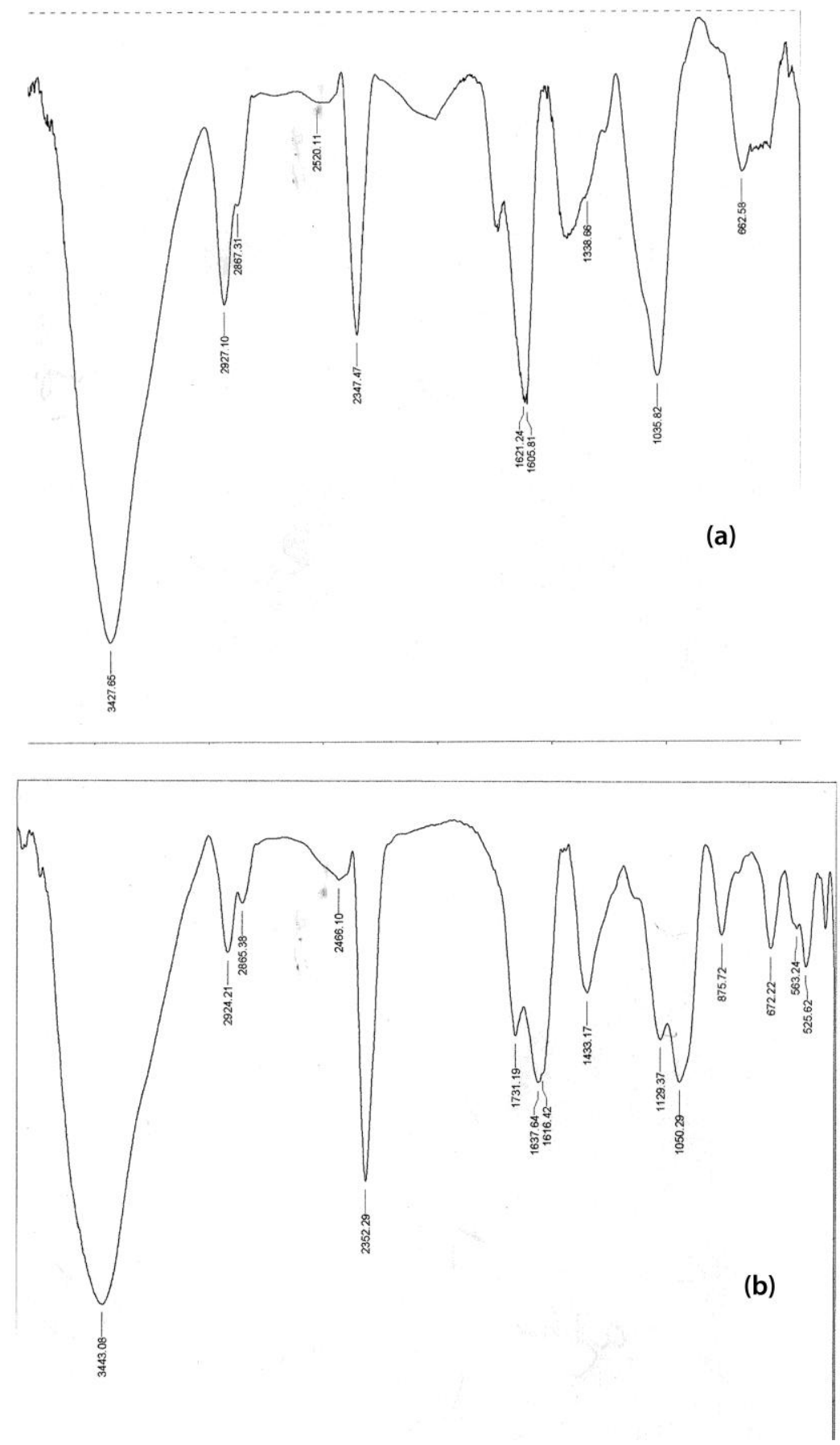
FT-IR spectrum is a useful tool to identify the functional groups present in a molecule, as each specific chemical bond often has a unique energy absorption band and can obtain structure band information and study of strength and fraction of hydrogen bonding. Fig 1(a and b) are spectra of synthesized MOH@n-HAp/Alg biocomposite and fluoride sorbed MOH@n-HAp/Alg composite respectively. The strong absorption band observed at 525, 563, 672 and $875 \mathrm{~cm}^{-1}$ which are attributed to the stretching and bending of $\mathrm{PO}_{4}{ }^{3-}$ of MOH@n-HAp/Alg(M.G. Ma et al, 2006). In addition, alginate also has a strong band at $1050 \mathrm{~cm}^{-1}$ (H.H, Jin et al, 2008). Thus the observed broad band at 1050 $\mathrm{cm}^{-1}$ is attributed to the overlap of C-O-C stretching of $\mathrm{Alg}$ and $\mathrm{PO}_{4}{ }^{3-}$ stretching of n-Hap(Kalimuthupandi et al, 2015). The absorption band at $1637,1731,2352$, and $2924 \mathrm{~cm}^{-1}$ shows the stretching vibration of $\mathrm{C}=\mathrm{C}, \mathrm{C}=\mathrm{O}, \mathrm{C} \equiv \mathrm{C}$ and $\mathrm{C}-\mathrm{H}$ group respectively. The band 2865 and $2924 \mathrm{~cm}^{-1}$ is attributed to the $\mathrm{O}-\mathrm{H}$ band in alcoholic group. The intensity of the band $3443 \mathrm{~cm}^{-1}$ in the fluoride sorbed MOH@n-HAp/Alg biocomposite was decreased due to the exchangeable hydroxyl anion present in the composite was replaced by fluoride ions.

\section{XRD analysis:-}

Seifert Analyze

Seifert Analyze

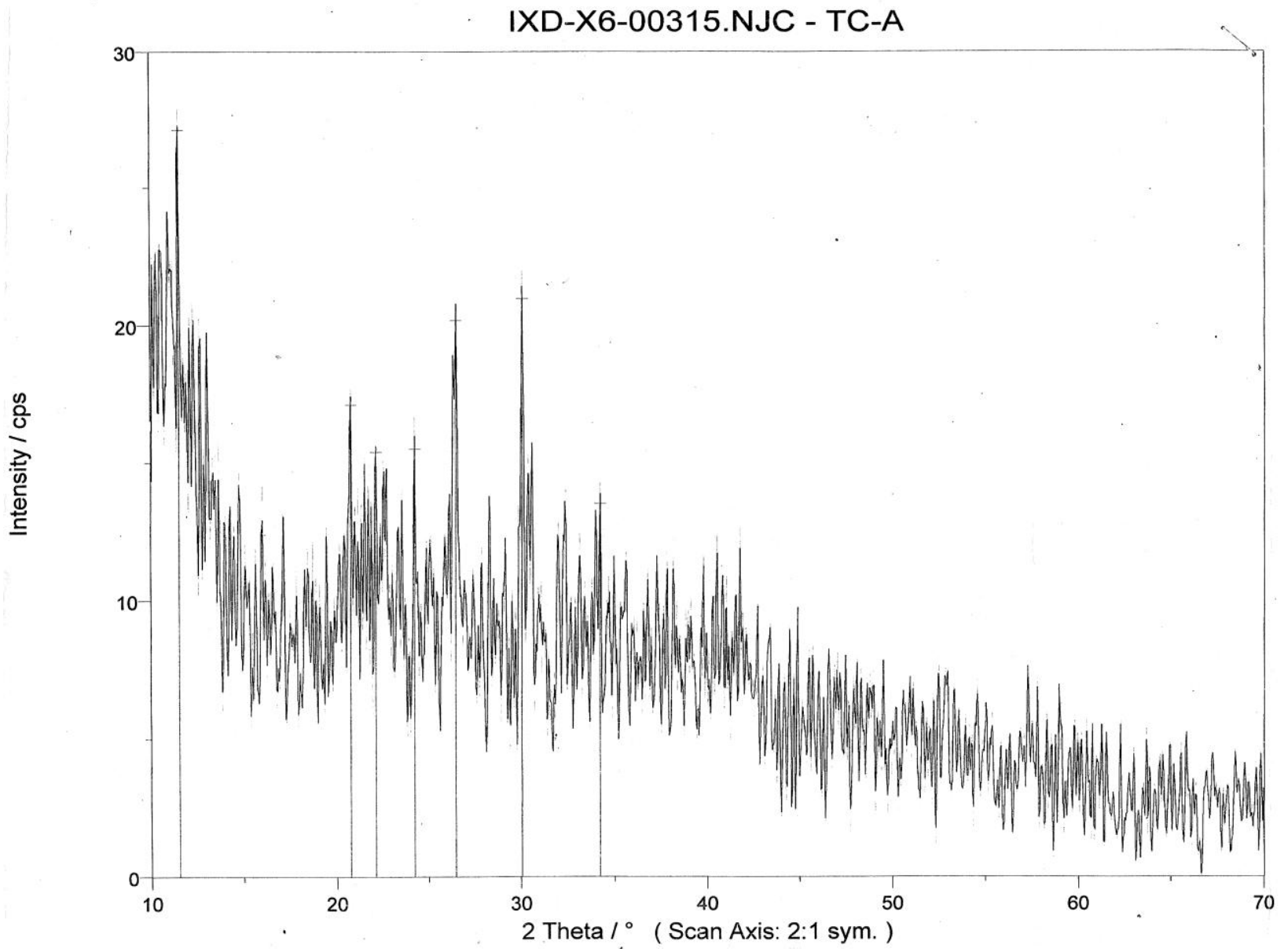

Figure 2:- XRD curves of MOH@n-HAp/Alg biocomposite

The X-ray powder patterns of composites are shown in the figure 2. The average particle size was calculated using Debye Scherer's formula

$\mathrm{d}=\mathrm{k} \lambda / \beta \cos \theta$

' $\beta$ ' is the full width at half maximum(FWHM), ' $\theta$ ' is the diffraction angle, ' $\lambda$ ' is the wavelength, ' $d$ ' is the particle size and ' $k$ ' is the Scherrer constant.

The average particle size of biocomposite from XRD was found to be $4.09 \mathrm{~nm}$. The composite peaks are in between $20^{\circ}$ and $30^{\circ}$. Similarly (Shihabudeen et al, 2006, Eskandarpour et al, 2008 and sivakumar et al, 2012) observed the poorly crystalline nature of sorbents in their study for the removal of fluoride in aqueous solution. 


\section{SEM and EDAX analysis:-}

The structural surface of the sorbent was studied with a scanning electron microscope(SEM) and the element composition before and after fluoride sorption was examined by energy dispersive X-ray analysis(EDAX). SEM images of MOH@n-HAp/Alg and fluoride sorbed MOH@n-HAp/Alg biocomposites are presented in Figure 3(a and b) respectively.

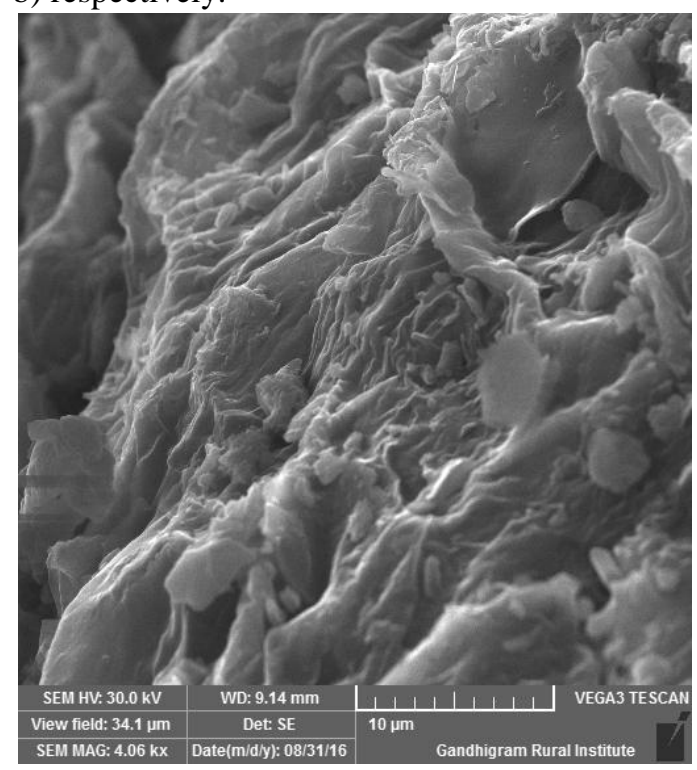

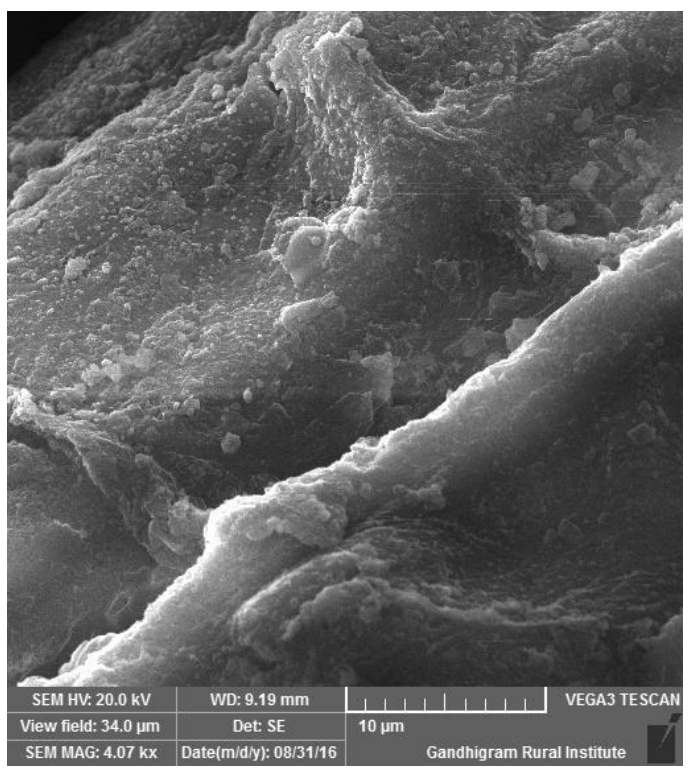

(b)

Figure 3:- SEM images of (a) MOH@n-HAp/Alg and (b) fluoride sorbed MOH@n-HAp/Alg biocomposite.

The particles had irregular surface with a porous lock, containing large number of wavy and highly broken edges. These images are clearly shown the difference in surface morphologies of these composites. After reaction with fluoride, the composite porous was partly destroyed and this might be attributed to deposition of fluoride over the pores of biocomposite surface. This is further supported by EDAX analysis, which provides the direct conformation for the sorption of fluoride ions onto MOH@n-HAp/Alg biocomposite. In figure 4(a and b) is the EDAX spectra before and after analysis of composites confirm the presence of respective ions are present in the composite. The fluoride peak in the biocomposite confirmed the fluoride treated composite. 

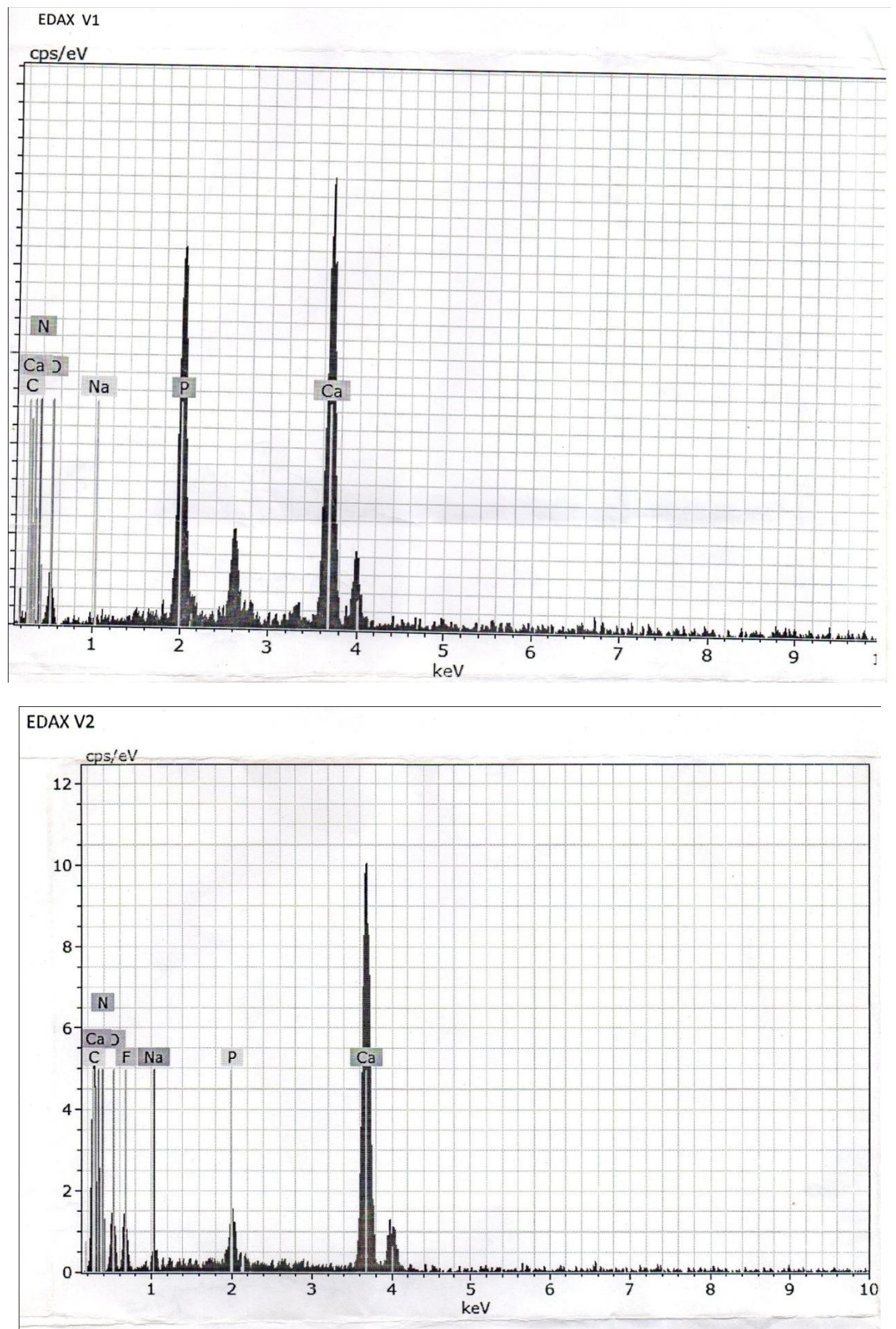

Figure 4:- EDAX spectra of (a) MOH@n-HAp/Alg and (b) fluoride sorbed MOH@n-HAp/Alg biocomposite 


\section{pH $\mathrm{H}_{\text {zpc }}$ analysis:-}

The $\mathrm{pH}_{\mathrm{zpc}}$ value of MOH@n-HAp/Alg biocomposite was found to be around 7.45. As shown in Figure 5, the DC of MOH@n-HAp/Alg biocomposite was influenced by the solution $\mathrm{pH}$ and it indicates that the maximum fluoride sorption capacity obtained at around $\mathrm{pH} 7$ and then decreased sharply with increase in $\mathrm{pH}$. The change in the $\mathrm{pH}_{\mathrm{zpc}}$ the biocomposite will confirm the surface morphological changes in the composite.

\section{Effect of pH:-}

The pH had some significant influence on sorption of fluoride by MOH@n-HAp/Alg biocomposite, because it can affect the surface charge of the adsorbent. The adsorption of fluoride ions onto the biocomposite adsorbents was analyzed at five different initial $\mathrm{pH}$ levels, viz., 2,4,6,7 and 9 and keeping other parameters as constant. The $\mathrm{pH}$ of the working solution was controlled by adding dilute $\mathrm{HCl} / \mathrm{NaOH}$ solution. In Figure 5 the biosorbent was effective in the $\mathrm{pH}$ range 6.0 and 7.5 with a maximum sorption of $85 \%$ at $\mathrm{pH} 7.1$ and the extent of sorption of fluoride decreased considerably above $\mathrm{pH} 7.5$ or below $\mathrm{pH} 4$. Some sorption was $>80 \%$ at the natural $\mathrm{pH}$ of aqueous sodium fluoride solution as prepared therefore, all the subsequent experiments were carried out without adjusting the $\mathrm{pH}$ of the fluoride solution. The effects of $\mathrm{pH}$ on fluoride adsorption by $\mathrm{MOH} @ \mathrm{n}-\mathrm{HAp} / \mathrm{Alg}$ is similar to what has been observed for fluoride adsorption onto various other adsorbents like lanthanum incorporated Chitosan beads(A. Banswal et al, 2009), tamarind fruit cover(N.P. Kumar et al, 2012) and neem leaf powder(Ranjan Kr Bharali et al, 2015). The increase in the $\mathrm{pH}$ value decreases the sorption of fluoride as the deprotonation on the sorbent commences. This results in decreasing the electrostatic force at attraction between the sorbent and sorbate ions. To understand the fluoride sorption behavior under different $\mathrm{pH}$ values, the following reactions are considered(M.S. Onyango et al, 2006, M.S. Onyango et al, 2006).

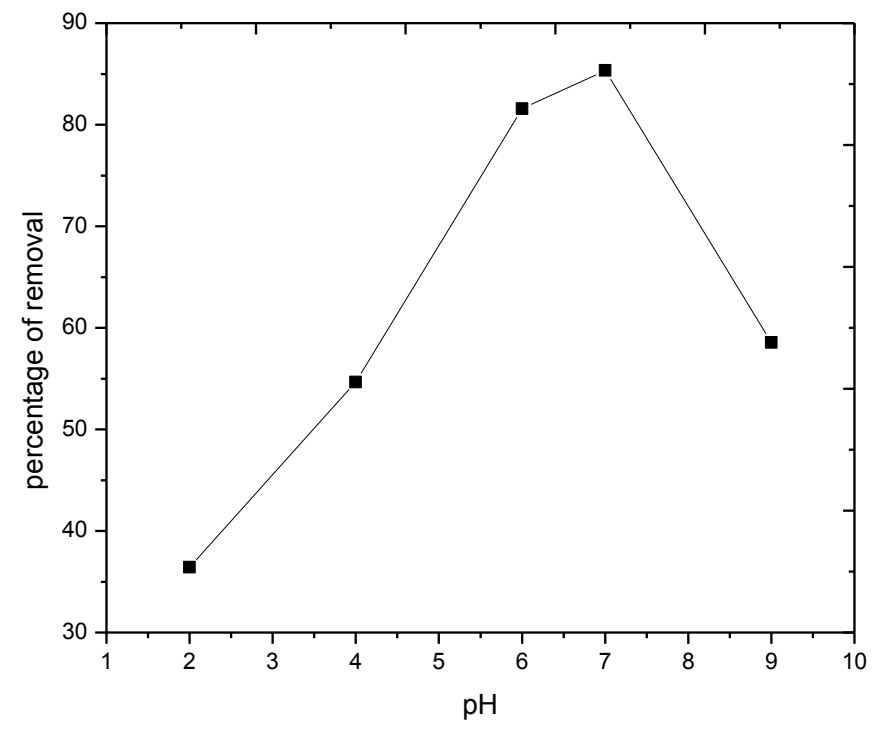

Figure 5:- Effect of solution $\mathrm{pH}$ on the $\mathrm{MOH} @ \mathrm{n}-\mathrm{HAp} / \mathrm{Alg}$ composite in presence of 13mg/L initial fluoride

$\mathrm{HF} \leftrightarrow \mathrm{H}^{+}+\mathrm{F}$ concentration, $0.1 \mathrm{~g}$ dosage with $60 \mathrm{~min}$. contact time at $301 \mathrm{~K}$.

$$
\begin{aligned}
& \mathrm{MOH} @ \text { n-HAp/Alg-OH + } \mathrm{H}^{+} \leftrightarrow \mathrm{MOH} @ n-H A p / A l g-\mathrm{OH}_{2}{ }^{+} \\
& \mathrm{MOH} @ \mathrm{n}-\mathrm{HAp} / \mathrm{Alg}-\mathrm{OH}+\mathrm{OH}^{-} \leftrightarrow \mathrm{MOH} @ \mathrm{n}-\mathrm{HAp} / \mathrm{Alg}-\mathrm{O}^{-} \\
& \mathrm{MOH} @ \mathrm{n}-\mathrm{HAp} / \mathrm{Alg}-\mathrm{OH}_{2}{ }^{+}+\mathrm{F}^{-} \leftrightarrow \mathrm{MOH} @ \mathrm{n}-\mathrm{HAp} / \mathrm{Alg}-\mathrm{F}+\mathrm{H}_{2} \mathrm{O} \\
& \mathrm{MOH} @ \mathrm{n}-\mathrm{HAp} / \mathrm{Alg}-\mathrm{OH}+\mathrm{F}^{-} \leftrightarrow \mathrm{MOH} @ \mathrm{n}-\mathrm{HAp} / \mathrm{Alg}-\mathrm{F}+\mathrm{OH}^{-}
\end{aligned}
$$

\section{Effect of Contact time:-}

The effect of contact time on fluoride sorption by MOH@n-HAp/Alg is shown in Figure 6. It was found that the extent of sorption increased with the increase in time(min.) upto $60 \mathrm{~min}$. and after this time interval, the sorption was almost constant. This indicated that the contact time for MOH@n-HAp/Alg biocomposite-fluoride interactions to reach equilibrium was just over $60 \mathrm{~min}$. Therefore, this time interval was maintained constant for the next set of 
experiments. The amount of adsorption is higher in initial stages may be due to the fact that initially all the sorption sites were vacant and can adsorb more fluoride ions from solution phase(S.Kumar et al, 2008).

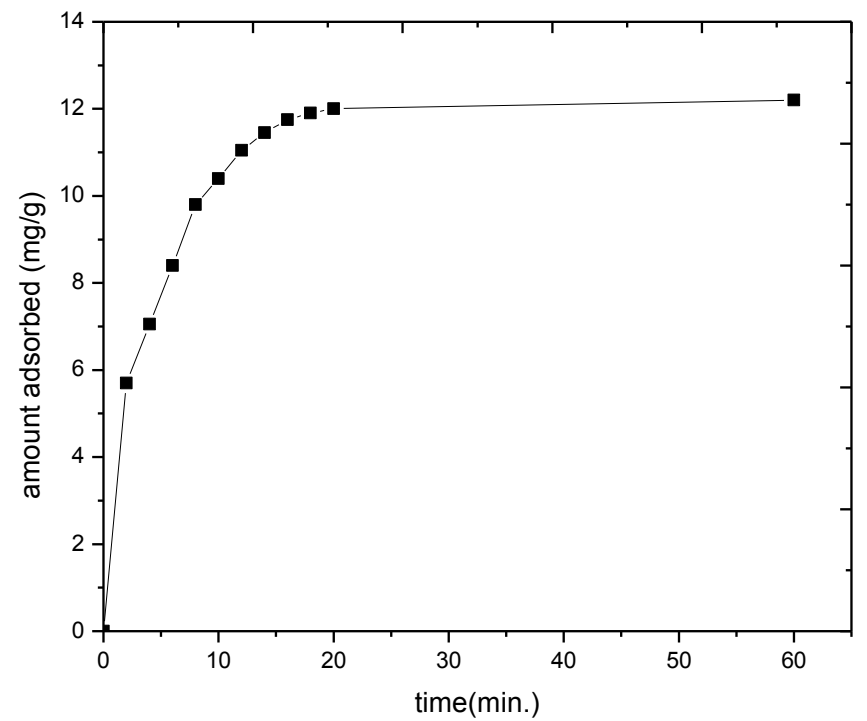

Figure 6:- Effect of contact time on the DC of MOH@n-HAp/Alg biocomposites in presence of 3mg/L initial fluoride concentration, $0.1 \mathrm{~g}$ dosage with neutral $\mathrm{pH}$ at $301 \mathrm{~K}$.

Effect of Co-anions:-

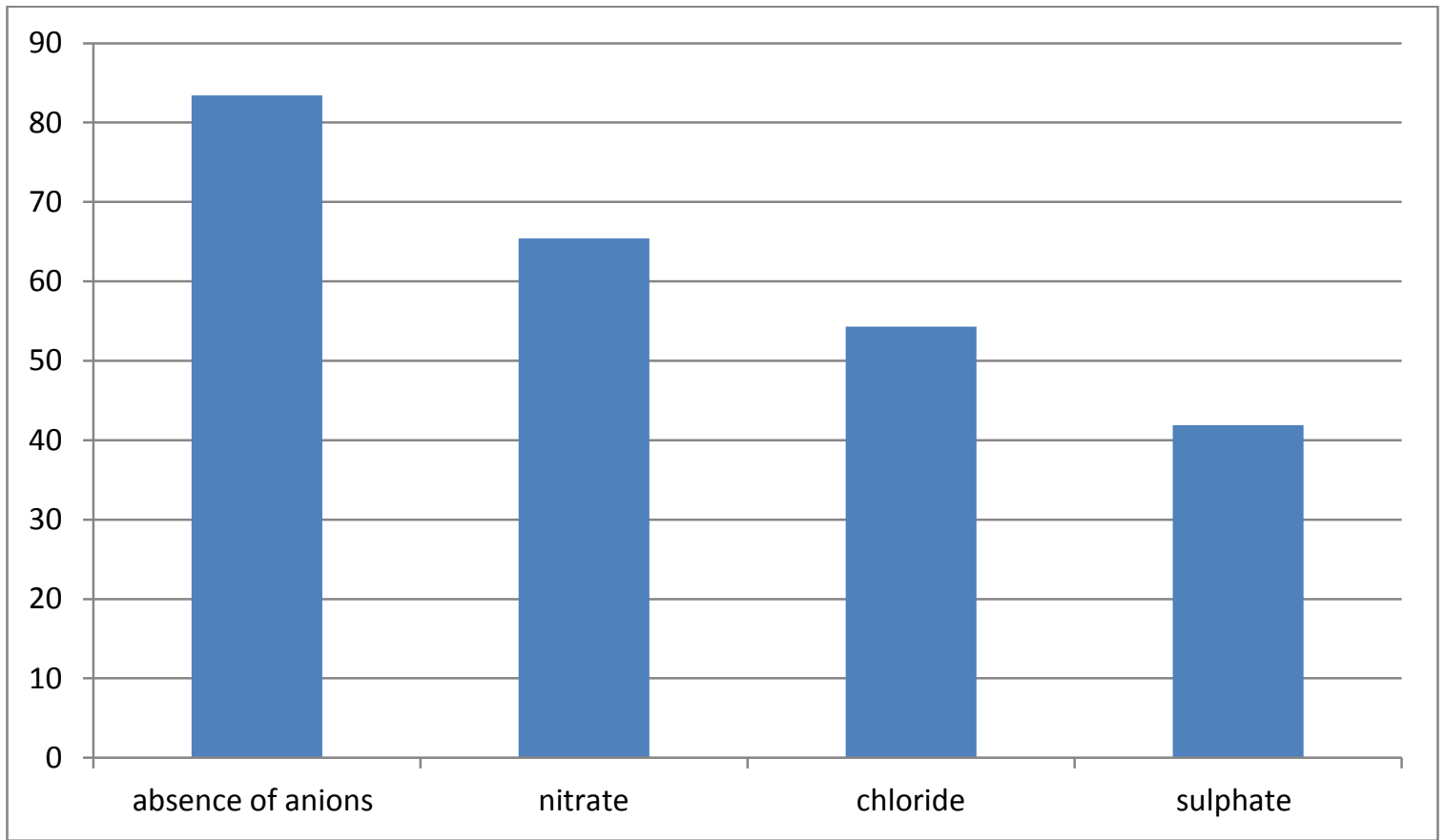

Figure 7:- Effect of presence of co-anions

The drinking water contains other anions in addition to fluoride. It is necessary to test the influence of these coanions on the MOH@n-HAp/Alg biocomposites. The co-anions like chloride, nitrate and sulphate are normally present in water. The effect of the amount of adsorption of the biocomposite with the fixed initial concentration of co-anions as $5 \mathrm{mg} / \mathrm{L}, 5 \mathrm{mg} / \mathrm{L}$ as the initial fluoride concentration and by keeping all other parameters as constant. In Figure 7 shows the percentage removal of fluoride in the presence of anions. It is clear that the fluoride removal is 
slightly decreased in the presence of chloride, sulphate and nitrate which may be due to high columbic repulsive forces and the size, charge, polarizability and electronegativity differences etc(S.S.Tripathy and A.M. Raichur, 2008). The preference of the sorption of anions by biocomposite may be the following order, fluoride $>$ nitrate>chloride>sulphate.

\section{Thermodynamic Studies:-}

The values of thermodynamic parameters are shown in Table 3 and it help to test the spontaneous occurrence of a given process as well as the viability of the operation at a given temperature. Thermodynamic parameters like standard free energy change $\left(\Delta \mathrm{G}^{\circ}\right)$, standard enthalpy change $\left(\Delta \mathrm{H}^{\circ}\right)$ and standard entropy change $\left(\Delta \mathrm{S}^{\circ}\right)$ were calculated by using standard method. The negative values of $\Delta \mathrm{G}^{\circ}$ for the biocomposite confirm the spontaneous nature of fluoride sorption. The positive value of $\Delta \mathrm{H}^{\circ}$ indicates that the defluoridation was governed by endothermic in nature. Biocomposite showed positive value of $\Delta \mathrm{S}^{0}$ which is a measure of randomness at the solid/liquid interface during fluoride sorption indicates the fluoride sorption is irreversible and stable. The $\mathrm{E}_{\mathrm{a}}$ value calculated from the slope of the plot was found to be $-5.062 \mathrm{~kJ} / \mathrm{mol}$ lesser $\mathrm{E}_{\mathrm{a}}$ value faster the reaction.

Table 1:- Thermodynamic parameters of the bioadsorbent

\begin{tabular}{|c|c|c|c|c|}
\hline Temp.(K) & $\Delta \mathrm{G}^{\mathrm{o}} \mathrm{kJ} / \mathrm{mol}$ & $\Delta \mathrm{H}^{\mathrm{o}} \mathrm{kJ} / \mathrm{mol}$ & $\Delta \mathrm{S}^{\mathrm{o}} \mathrm{kJ} / \mathrm{mol}$ & $\mathrm{E}_{\mathrm{a}} \mathrm{kJ} / \mathrm{mol}$ \\
\hline 301 & -39.04 & 4.86 & 0.029 & -5.062 \\
311 & -41.89 & & & \\
\\
321 & -44.84 & & & \\
\hline
\end{tabular}

\section{Adsorption isotherm analysis:-}

The equilibrium data for fluoride sorption onto biocomposite are shown in Table 2. The equilibrium data have been analyzed by the linear regression of isotherm model equations viz., Langmuir(I. Langmuir, 1916), Freundlich(H.M.F. Freundlich, 1906), Temkin(Temkin, M.J and Pyzhev, V, 1940) and D-R isotherm(M.M. Dubinin, 1960).

Table 2:- Various isotherm parameters of MOH@n-HAp/Alg biocomposites

\begin{tabular}{|c|c|c|c|c|}
\hline Isotherms & Langmuir & Freundlich & Temkin & $\mathrm{D}-\mathrm{R}$ \\
\hline Parameters & $\mathrm{Q}_{0}=121.0$ & $\mathrm{n}=0.8423$ & $\mathrm{~K}_{\mathrm{T}}=2.85$ & $\mathrm{q}_{\mathrm{m}}=10320.5$ \\
& $\mathrm{~b}=0.1507$ & $1 / \mathrm{n}=1.215$ & $\mathrm{~B}_{\mathrm{T}}=44.22$ & $\beta=-2.49 X 10^{-7}$ \\
& $\mathrm{R}_{\mathrm{L}}=0.481$ & $\mathrm{~K}_{\mathrm{F}}=22.14$ & $\mathrm{r}=0.9801$ & $\mathrm{E}=1.42$ \\
& $\mathrm{r}=0.7456$ & $\mathrm{r}=0.9843$ & $\mathrm{sd}=5.12 \mathrm{E} 1$ & $\mathrm{r}=0.9277$ \\
& $\mathrm{sd}=7.62 \mathrm{E}-5$ & $\mathrm{sd}=0.0093$ & & $\mathrm{sd}=0.2199$ \\
\hline
\end{tabular}

The linear plot of $\mathrm{C}_{\mathrm{e}}$ vs $\mathrm{C}_{\mathrm{e}} / \mathrm{q}_{\mathrm{e}}$ indicates the applicability of Langmuir isotherm. The calculated values of $\mathrm{Q}_{\mathrm{o}}$ and $\mathrm{b}$ are listed in table 2. The $\mathrm{R}_{\mathrm{L}}$ values lie in the range between 0 and 1 indicates the sorption process was favourable. The applicability of Fruendlich equation was indicated by the linear plot of $\log C_{e} v s \log q_{e}$. The obtained ' $n$ ' and $\mathrm{K}_{\mathrm{F}}$ values are in table 2. The values of $\mathrm{n}$ lies between 1 and 10 represent favourable condition for sorption. Temkin isotherm was carried out by plotting $\operatorname{lnC}_{\mathrm{e}}$ vs $\mathrm{q}_{\mathrm{e}}$ (Fig. The value of $\mathrm{K}_{\mathrm{T}}$ and $\mathrm{B}_{\mathrm{T}}$ were determined from the slope and intercept of the linear plot and are listed in table 2. The high ' $r$ ' values and the lower sd values indicate the applicability of particular isotherm. The linear plot of $\varepsilon^{2} \mathrm{vs} \operatorname{lnq}_{\mathrm{e}}$ indicates the applicability of D-R isotherms. The values of $\mathrm{q}_{\mathrm{m}}, \beta$ and $\mathrm{E}$ are shown in table 2 . The $\mathrm{E}$ value ranges from 1 to $8 \mathrm{~kJ} / \mathrm{mol}$ for physical sorption and from 9 to $16 \mathrm{~kJ} / \mathrm{mol}$ for chemical adsorption(A.Sari et al, 2007, R.Donat et al, 2005). From the result the value of $\mathrm{E}$ which is $1.42 \mathrm{~kJ} / \mathrm{mol}$ may suggest that the mechanism for the fluoride sorption on biocomposite is of physical sorption in nature.

\section{Sorption kinetic studies:-}

The sorption kinetics describes the sorbate uptake rate that can determine the residence time of sorbate at the solidsolution interface. The sorption processes are analyzed by using reaction based models, including pseudo-first order (A.A. Khan and R.P. Singh, 1987) models and pseudo-second order (S. Langergen, 1898) models. The linear plots of $\log \left(\mathrm{q}_{\mathrm{e}} \mathrm{-q}\right)$ against ' $\mathrm{t}$ ' give straight line indicate the applicability of pseudo-first-order model. The slope of the straight line plot of $\log \left(\mathrm{q}_{\mathrm{e}}-\mathrm{q}\right)$ against ' $\mathrm{t}$ ' sorption at different temperatures viz. 301,311 and $321 \mathrm{~K}$ give the value of the pseudo-first order rate constant $\left(\mathrm{k}_{\mathrm{ad}}\right)$ and $\mathrm{r}$ values are listed in Table 3. The pseudo-second-order equation can be found out experimentally by plotting $t / q_{t}$ against ' $t$ '. The values of $\mathrm{q}_{\mathrm{e}}, \mathrm{k}_{2}$ and ' $\mathrm{r}$ ' if the pseudo-second-order model were obtained from the plots of $t / q_{t}$ vs $t$ for fluoride sorption at different temperatures viz 301,311 and $321 \mathrm{~K}$ of the composite are presented in table 3 . The values of $\mathrm{q}_{\mathrm{e}}$ increase with the increase in temperature indicating the fluoride 
sorption increases with increase in temperature. The higher ' $r$ ' values obtained for pseudo-second-order model than pseudo-first-order model indicate the applicability of the pseudo-second-order model than pseudo-first-order model. For a solid-liquid sorption process, the solute transfer in usually characterized by intra-particle diffusion control (W.J. Weber and J.C.Morris, 1964). The straight line plot of $\mathrm{q}_{\mathrm{t}} \mathrm{vs} \mathrm{t}^{1 / 2}$ indicates the applicability of intraparticle diffusion model. The $\mathrm{k}_{\mathrm{ad}}, \mathrm{k}_{2}, \mathrm{k}_{\mathrm{id}}$ and ' $\mathrm{r}$ ' values are illustrated in table 3 . Based on the sd values shown in Table 3 , it is clear that the lower sd values of pseudo-second-order is suitable for describing the sorption kinetics of fluoride on MOH@n-HAp/Alg biocomposite.

Table 3:- Kinetic model for MOH@n-HAp/Alg biocomposite

\begin{tabular}{|c|c|c|c|c|c|c|c|}
\hline \multirow[b]{2}{*}{$\begin{array}{c}\text { Kinetic } \\
\text { model }\end{array}$} & \multirow[b]{2}{*}{ Parameters } & \multicolumn{6}{|c|}{$301 \mathrm{~K}$} \\
\hline & & $3 \mathrm{mg} / \mathrm{L}$ & $5 \mathrm{mg} / \mathrm{L}$ & $7 \mathrm{mg} / \mathrm{L}$ & $9 \mathrm{mg} / \mathrm{L}$ & $11 \mathrm{mg} / \mathrm{L}$ & $13 \mathrm{mg} / \mathrm{L}$ \\
\hline \multirow[t]{3}{*}{ First order } & $\mathrm{k}_{\mathrm{ad}}$ & 0.151 & 0.200 & 0.065 & 0.167 & 0.131 & 0.169 \\
\hline & $\mathrm{r}$ & 0.937 & 0.996 & 0.986 & 0.958 & 0.965 & 0.908 \\
\hline & $\mathrm{sd}$ & 0.0149 & 0.198 & 0.007 & 0.152 & 0.080 & 0.378 \\
\hline \multirow[t]{4}{*}{ Second order } & $\mathrm{q}_{\mathrm{e}}$ & 22.98 & 14.32 & 27.17 & 43.47 & 51.28 & 60.97 \\
\hline & $\mathrm{k}_{2}\left(\mathrm{X} 10^{-3}\right)$ & 8.35 & 19.00 & 11.00 & 4.90 & 4.57 & 4.54 \\
\hline & $\mathrm{r}$ & 0.981 & 0.998 & 0.988 & 0.987 & 0.987 & 0.988 \\
\hline & $\mathrm{sd}$ & 0.005 & 0.024 & 0.010 & 0.005 & 0.003 & 0.002 \\
\hline \multirow{3}{*}{$\begin{array}{c}\text { Intra particle } \\
\text { diffusion }\end{array}$} & $\mathrm{k}_{\mathrm{id}}$ & 0.686 & 1.129 & 1.147 & 2.09 & 2.37 & 2.62 \\
\hline & $\mathrm{r}$ & 0.869 & 0.999 & 0.999 & 0.986 & 0.996 & 0.999 \\
\hline & $\mathrm{sd}$ & 5.11 & 0.127 & 0.126 & 4.85 & 1.696 & 0.308 \\
\hline
\end{tabular}

\section{Field Study:-}

In order to test the suitability of MOH@n-Hap/Alg biocomposite at field conditions, fluoride contaminated water was collected in a nearby village. About $0.05 \mathrm{~g}$ of the bio composite was added to $100 \mathrm{~mL}$ of fluoride water sample and the contents were shaken with constant time at room temperature. The obtained results are presented in Table 4. There is a significant reduction in the levels of other water quality parameters in addition to fluoride. It is evident from the result that the biocomposite can be effectively employed for removing the fluoride from water.

Table 4:- Field trial results of the biocomposite

\begin{tabular}{|c|c|c|}
\hline Water quality parameter & Before treatment & After treatment \\
\hline $\mathrm{F}^{-}(\mathrm{mg} / \mathrm{L})$ & 3.14 & 7.94 \\
\hline $\mathrm{p}^{\mathrm{H}}$ & 6.91 & 1.16 \\
\hline Total hardness $(\mathrm{mg} / \mathrm{L})$ & 200 & 176 \\
\hline Total dissolved solid $(\mathrm{mg} / \mathrm{L})$ & 126 & 95 \\
\hline
\end{tabular}

\section{Conclusions:-}

In this study, the following conclusions were drawn: the DCs of biocomposite was influenced by the $\mathrm{pH}$ of the medium and slightly lowered in the presence of co-anions. The sorption of fluoride onto MOH@n-HAp/Alg biocomposite follows Freundlich Isotherm. The nature of fluoride removal was spontaneous and endothermic. The kinetics of the reaction followed pseudo-second-order model. Field studies indicated that the biocomposite could be used as effective fluoride removal sorbents. The developed MOH@n-HAp/Alg biocomposite could be an effective, eco-friendly and economical biocomposite for the removal of fluoride in water.

\section{References:-}

1. M.R. Boldaji, A.H. Mahvi, S.Dobaradaran, S.S. Hosseini, (2009): Evaluating the effectiveness of a hybrid sorbent resin in removing fluoride from water. Int. Journal of Environmental Science and Technology. 6(4): 629-632.

2. Y.C.Lu, E.Kir, M.Ersoz, (2002): Removal of fluoride from aqueous solution by using red mud. Sep. Purification Technol., 28: 81-86.

3. M. Maharamanlighu, J.Kizilcikli, I.O. Bicer, (2002): Adsorption of fluoride from aqueous solution by acid treated spent bleaching earth. J.Fluoride Chem., 115: 41-17. 
4. T.J. Song, (1978): Treatment technology to meet the interim primary drinking water regulations from inorganics, J.Am.Water Works Assoc., 70: 105-111.

5. V.Sivasankar, T.Ramachandramoorthy, Achandra Mohan, (2010): Fluoride removal from water using activated and $\mathrm{MnO}_{2}$-coated tamarind fruit(tamarindous indica) shell: Batch and column studies, 177: 719-729.

6. A.Sivakamy, K.P.Singh, D.Mohan, M. Maruthamuthu. (2001): Studies on defluoridation of water by coal-based sorbents, J.Chem.Tech.Biotech., 76: 717-722.

7. A.K.Chaturredi, K.P.Yadav, K.C. Pathak, V.N.Singh. (1990): Defluoridation of water by adsorption on fly ash, Water Air Soil Pollution, 49: 51-61.

8. N. Azhar, A. Turkman, (2000): Defluoridation in drinking waters, Water Sci., Technol., 42: 403-407.

9. M.Castel, M.O. Schweizer, simonnot, M.Sardin, (2000): Selective removal of fluoride ions by a two way ionexchange cyclic process. Chem.Eng.Sci., 55: 2341-3352.

10. Z.Amor, B.Barionb, N. Mameri, M.Tuky, S.Nicoles, A. Elmideoui, (2001): Fluoride removal from brackish water by electrodialysis, Desalination, 114: 45-51.

11. Al E. Shen, X.M.Chen, P.Gao, G.H.Chen, (2003): Electrochemical thermal of fluoride ions from industrial wastewater. Chem. Eng. Sci., 58: 987-993.

12. S.O. Lesmana, N.Febriana, F.E. Soetaredjo, J.Sunarso, S. Ismadji, (2009): Studies on potential applications of biomass for the separation of heavy metals from water and wastewater, Biochem. Eng.J., 44: 19-41.

13. Varma, A.J.Deshpande, S.V., and Kennady, J.F., (2004): Metal complexation by chitosan and its derivates: a review, carbohydrate polymers, 55: 77-93.

14. Viswanathan, N. and Meenakshi.S, (2009 a): Synthesis of $\mathrm{Zr}(\mathrm{IV})$ entrapped chitosan polymeric matrix for selective fluoride sorption. Colloids and surfaces Biointerfaces, 72: 88-93.

15. Jayakumar, R. Rajkumar, M., Freitas, H., Selvamurugan, N. Nair, S.V. Furuike, T. and Tamura, H, (2009): Preparation, characterization, bioactive and metal uptake studies of alignate/phosphorylated chitin blends films. International J. of biological macromolecules, 44: 107-111.

16. Sairam Sundaram. C., Viswanathan, N. and Meenakshi, S., (2009): Fluoride sorption by nano hyhdroxyapatite/chitin composite. Journal of hazardous materials, 172: 147-151.

17. Googerdchian, F. Moheb, A., and Emadi, R. (2012): Lead Sorption properties of nanohydroxyapatite-alignate composite adsorbents. Chemical Engineering J., 200-202: 471-479.

18. Yu, X. Tong, S. Ge, M. and Zuo, J. (2013): Removal of fluoride from drinking water by cellulose @ hydroxyapatite nanocomposites. Carbohydrate Polymers, 92: 269-275.

19. Pandi, K. and Viswanathan, N. (2014): Synthesis of alginate bioencapsulated nano-hydroxyapatite composite for selective fluoride sorption. Carbohydrate polymers, 112: 662-667.

20. V.Sivasankar, T. Ramachandramoorthy, A.Chandramohan, (2010): Fluoride removal from water using activated and $\mathrm{MnO}_{2}$-coated Tamarind fruit (Tamarindus indica) shell: Batch and column studies, 177: 719-729.

21. Rajan Kr. Bharati , Krishna, G. Bhattacharryya, (2015): Biosorption of fluoride on neem(Azadirachta indica) leaf powder, 559: 1-8.

22. APHA, standard methods for the examination of water and wastewater, (2005): American Public Health Association, Washington, DC.

23. Lopez-Ramon, M.V. Stoeckli, F., Moreno-Castilla, C., and Carrasco-marin, F., (1999): On the characterization of acidic and basic surface sites on carbons by various techniques. Carbon, 37: 1215-1221.

24. M.G. Ma, Y.J.Zhu, J. Chang, (2006): J.Phys.Chem. B, 110(9): 14226-14230.

25. H.H, Jin, C.H. Lee, W.K. Lee, J.K.Lee, H.C., Park, S.Y.Yoon, (2008): Mater., Lett., 62: 1630-1633.

26. Kalimuthupandi, Natrayasamy Viswanathan, (2015): Enhanced defluoridation and facile separation of magnetic nano-hydroxyapatite/alignate composite. International J. of Biological Macro molecules, 1-9.

27. M.M. Shihabudeen, S.Atul Kumar, L.Philip, (2006): Manganese oxide-coated alumina: a promising sorbet for the fluoridation of water, Water Res., 40: 3497-3506.

28. A. Eskandarpour, M.S. Onyango, A. Ochieng, S.Asari, (2008): Removal of fluoride ions from aqueous solution at low pH using schwertmannite, J.Hazard. Mater., 152: 571-579.

29. V.Sivakumar, S.Rajkumar, S.Murugesh, A. Darchen, (2012): Tamarind(Tamarindus iindica) fruit shell carbon: a Calciu-rich promising adsorbent for fluoride removal from groundwater., J. Hazar. Mater., 225-226: 164-172.

30. A. Banswal, D. Thakre, N. Labhshetwar, S. Meshram, S. Rayalu, (2009): Fluoride removal using lanthanum incorporated chitosan beads, Colloids surface. B, 74(1): 216-224.

31. N.P. Kumar, N.S. Kumar, A. Krishnaiah, (2012): Defluoridation of water using tamarind(Tamarindus indica) fruit cover: Kinetics and equilibrium studies, J.Chil. Chem. Soc., 57(3): 1224-1231.

32. Ranjan Kr Bharali, Krishna G. Bhattacharyya, (2015): Biosorption of fluoride of neem (Azadirachta indica) leaf powder. Journal of Environmental Chemical Engineering, 1-8. 
33. M.S. Onyango, Y.Kojima, O. Aoyi, E.C., Bernardo, M.Matsuda, (2006): Adsorption equilibrium modeling and solution chemistry dependence of fluoride removal from water by trivalent-cation exchange zeolite. J.Colloid.Interface Sci., 279: 341-350.

34. M.S. Onyango, Y. Kojima, D. Kachar, M. Kubota, H. Matsuda, (2006): Uptake of fluoride by $\mathrm{Al}^{3+}$-pretreated low-silica synthetic. Zeolites adsorption equilibrium and rate studies. Sep.Sci.Technol., 41: 1-22.

35. S.Kumar, A.Gupta, J.P. Yadav, (2008): Removal of fluoride by thermally activated carbon prepared from neem (Azadirahta indica) and kikar (Acacia Arabica) leaves, J.Environ. Biol., 29(2): 227-232.

36. S.S.Tripathy, A.M. Raichur, (2008): Abatement of fluoride from water using Manganese dioxide-coated activated alumina. J.Hazard.Mater., 153: 1043-1051.

37. I. Langmuir, (1916): The constitution and fundamental properties of solids and liquids, Journal ofo American Chemical Society, 38: 2221-2295.

38. H.M.F. Freundlich, (1906): Uber die adsorption in lolsungen. International Journal of Research in Physical Chemistry and Chemical Physics, 57A: 385-470.

39. Temkin, M.J., and Pyzhev, V. (1940): Recent modifications to Langmuir isotherms. Acta Physiochim, URSS 12: $217-222$.

40. M.M. Dubinin, (1960): The potential theory of adsorption of gases and vapors for adsorbents with energetically non-uniform surface, Chem. Rev. 60: 235-266.

41. A.Sari, M.Tuzen, M.Soylak, (2007): Adsorption of $\mathrm{Pb}(\mathrm{II})$ and $\mathrm{Cr}(\mathrm{III})$ from aqueous solution on Celtek clay, J.Hazard.Mater. B, 144: 41-46.

42. R.Donat, A.Akdogan, E.Erdem, H.Cetisli, (2005): J.Colloid Interf.Sci., 286: 43-52.

43. A.A. Khan, R.P. Singh, (1987): Colloids Surface, 24: 33-42.

44. S. Langergen, (1898): About the theory of so-called adsorption of soluble substances, Kungliga svenska veensk Handl, 24: 1-39.

45. W.J. Weber, J.C.Morris, (1964): J.Sanit.Eng.Div., 90: 79-91. 